\title{
DreamSenseMemory - a Gestalt-based dream-work approach embracing all our senses
}

\author{
Brigitte Holzinger, Franziska Nierwetberg, Larissa Cosentino, Lucille Mayer \\ Institute for Consciousness and Dream Research, Vienna, Austria
}

\begin{abstract}
Gestalt therapists believe that their task is to help their clients to experience repressed, ambivalent, and unpleasant things in order to accept and implement them in their whole self. To implement those 'things', those elements of the self, they need to be uncovered first, which is a process that often is achieved by dream work, as messages from the unconscious that are stuck in our dreams can be revealed by certain Gestalt-therapy methods. The method in focus is the newly developed DreamSenseMemory technique which is based on neurological findings on how the senses at play influence memory processing. Dream work with the DreamSenseMemory method has the advantage that by using this method on a regular basis, dream content will not only be remembered more often but also in more detail. Thus, effectively supporting dream work and its process of understanding the message of the unconscious, accepting the elements withing and implementing them in the self.
\end{abstract}

Key words: Gestalt therapy; Gestalt theory; psychotherapy.

Correspondence: Brigitte Holzinger, Institute for Consciousness and Dream Research, Canongasse 13/1, 1180 Vienna, Austria. Tel.: +4369910199042.

E-mail: info@schlafcoaching.org

Acknowledgements: we would like to express our sincere thanks to the editor and the reviewers for their careful work and thoughtful suggestions.

Contributions: $\mathrm{BH}$, conceptualization, manuscript: draft; $\mathrm{LC}$, research, translation; LM, additional research, manuscript: formatting; FN, research, citation, manuscript structure. The authors confirm being the only contributors of this work.

Conflict of interests: the authors declares no potential conflict of interests.

Ethics statement: ethical review and approval was not required for the study because no human participants were part of this study.

Consent for publication: all authors have approved the manuscript for publication.

Citation: Holzinger, B., Cosentino, L., Mayer, L., \& Nierwetberg, F. (2021). DreamSenseMemory - a Gestalt-based dream-work approach embracing all our senses. Research in Psychotherapy: Psychopathology, Process and Outcome, 24(2), 122-129. doi: 10.4081/ripppo.2021.529

Received for publication: 11 February 2021.

Revision received: 24 July 2021

Accepted for publication: 24 July 2021.

This work is licensed under a Creative Commons Attribution NonCommercial 4.0 License (CC BY-NC 4.0).

${ }^{\circ}$ Copyright: the Author(s), 2021

Licensee PAGEPress, Italy

Research in Psychotherapy:

Psychopathology, Process and Outcome 2021; 24:122-129

doi:10.4081/ripppo.2021.529

\section{Introduction: memory processing through senses}

Memory is based on all our senses, but while we have many descriptive words for visuals, it gets way trickier to put scents, touches, sounds or taste, into words. This is why we often avoid describing those elements of our memory in the first place. The result is that on a conscious level, we tend to ignore memories bound to the memory of the four non visual senses and rely mostly on visuals or on abstract thoughts for which we have an exhaustive vocabulary. The fact that this is the way our language developed, might already be a sign, that we find it harder to differentiate what we perceive through these four senses (Majid \& Levinson, 2011; Plümacher \& Holz, 2007). Nevertheless, our memory is indeed connected to not only the visual, but also to the four other senses. As an example, the visual and the verbal memory is enhanced if music improvisation is being played after the acquisition of verbal or visual information (Abrahan, Shifres, \& Justel, 2021). This example shows very well how important our senses are for the process of memorizing.

Freud coined the notion, that the dream is Via Regia to the unconscious (Freud, 1900). When we 'work' with dreams in psychotherapy, at first sight it might seem unusual to involve our senses instead of our cognitive abilities . Trying to recall dreams by letting the memories of sensations lead the way may lead more precisely to the unconscious and allow us to access memories we have not put into words or consciously memorized. For a better understanding, the story of a client suffering from unpleasant dreams will be described briefly. He came to me wanting to get rid of those dreams. As usual, I recommended writing down the dreams in order to work with them. This 
man however draw pictures of his dreams instead of writing them down. He drew his old apartment where he used to live with his mother, and his dreams took place. He drew the layout of the apartment and every room had a specific colour, that came to him naturally as he 'sensed' his dream. The only room having no colour was the bathroom. As we focused on the bathroom we found out he had suffered from abuse in this very room as he was a child and he had supressed the memory for all this time. Freud stated, that dreams are primary processes. They evolve directly from the unconscious, whereas secondary processed represent the relationship between the unconscious and reality (Busch, Leuzinger-Bohleber, \& Prokop, 2003; Freud, 1900). This leads to the assumption, that dreams are better understood by trying to remember them by the sensations they evoked rather than remembering them 'cognitively', which is a better fit for conscious memories. This consideration is also consistent with the principle of encoding-specificity (Flexser \& Tulving, 1978; Tulving \& Thomson, 1973). It states, that memories are retrieved more easily if the cue is similar to the encoding modalities. This means, that highly emotional memories are retrieved more efficient if the cue is highly emotional as well. The same holds for acoustic memories being retrieved more easily by acoustic cues.

\section{Aims of this paper}

This paper aims to explain the background, development and application of DreamSenseMemory (DSM; available as APP for android and IOS and online course, to be found at dreamworld.coachy.net/dreamsensememory/), that is an approach for dream work based on retrieveing sensual memory. With DSM we want to explore the unconscious of the dream by means of a more detailed visual approach and sensorial elements, as an additional way to access repressed memories and hidden messages. In the following sections we will explore this method more deeply, starting with its basic theoretical background Gestalt Therapy. Next we will give insights in the conceptualization of dreams in Gestalt Therapy and how to work with dreams in a therapeutic setting. Lastly, it will be described how those concepts and methods led to the development of DSM and what its specific properties and advantages are.

\section{Gestalt therapy: roots, concepts and ideas}

Relevant for the development of DSM is Gestalt theory and its influence on Gestalt therapy and Gestalt therapy theory. Gestalt therapy was essentially founded by Fritz Perls (1893-1970) and his wife Laura (1905-1990) and has its roots in Gestalt theory and Gestalt psychology as well as psychoanalysis (Hartmann-Kottek, 2000). It was also influenced by existentialism, ideas of Taoism, acting methods and individual authors such as Martin Buber and Paul Tillich (Bowman \& Nevis, 2005).

The main idea of Gestalt theory is that the Gestalt (German for 'shape', 'form', 'figure') is a complete, self-contained whole. The notion of Gestalt traces back to Christian von Ehrenfels (1859-1932), one of the first Gestalt theorists who coined the phrase "The whole is something other than the sum of its individual parts' (Ehrenfels, 1890). He argued that humans are able to recognize two melodies as identical even when no two notes in them are the same, so the melody forms a whole that is more than its individual parts and that can often be recognized easier than its parts (Wagemans, 2015). Other important founding fathers of Gestalt theory and Gestalt psychology were Kurt Goldstein (1878-1965), Max Wertheimer (1880-1943), Kurt Koffka (18861941), Wolfgang Köhler (1887-1967), Kurt Lewin (1890-1947) and Wolfgang Metzger (1899-1979) (Wagemans, 2015).

Gestalt theory postulates that we co-create the world in the act of perception (Koffka, 1935). In contrast to constructivism, however, it assumes that 'out there' exists a correlate of what is perceived. In the course of our existence each of us created the world as we ourselves see it today. The results of many psychological experiments, but also everyday experiences on the relativity of perception, can be explained with these assumptions of Gestalt theory (Lewin, 1963). A well-known example are the ambiguous figures or picture puzzles. Therefore DSM is driven by the client, not the therapist. Only the clients know their co-creation of the world, from which their dreams emerge.

In a nutshell the theoretical background of Gestalt therapy is Gestalt theory in general as described above, and especially the law of perception from Gestalt theory. This principle is transferred from perception into experience and called 'unfinished business'. It says, that an open Gestalt always urges for perfection, urges for completion, urges for closure (Metzger, 1936). Otherwise the so-called unfinished business pursues us in our thoughts and fantasies (Perls, 1972; Perls, Hefferline, Goodman, \& Perls, 1995). Thoughts such as 'Was there not something I still have to do?' or 'That doesn't leave me in peace!' or 'At some point I have to call someone and clarify this or that.' are constant reminders of an incomplete Gestalt. Such Gestalt elements come to the surface by themselves, we just have to deal with them and address the obvious. These elements sometimes enter our conscious being by emerging first in dreams.

Another crucial concept for the development of DSM, stemming from Gestalt therapy theory is based on the equation awareness $=$ the present $=$ reality (Yontef, 1993). In this equation DSM is embedded. To remember dreams better and more often, the awareness of all senses is needed to be fully grasping the present moment and to perceive the whole aspects of the present reality. In Gestalt therapy we try to bring the obvious to light, what 
appears on the surface, what can be perceived by or through the patient, i.e. can be seen, heard or smelled will be made clear. The resulting Gestalt can be worked upon in the frame of the therapist-patient relationship (Holzinger \& Klösch, 2013).

In Gestalt therapy and Gestalt therapy theory, we don't ask about the why, but about how and what. For instance, we ask what the structure of our life script is and how we can re-structure or rewrite it, if deemed necessary. The role of inner images is essential in the process of rewriting: 'In therapy, imagery can provide a special type of access to cognitive structures that allows the structures to be worked with in ways that the linear and analytical verbal techniques cannot.' (Edwards, 1989, p. 284). Please note, that we took the liberty to focus on the elements of Gestalt theory and Gestalt therapy and its theory, that have been crucial for the emergence of DSM. Other roots of Gestalt therapy such as psychoanalysis have only been mentioned.

\section{Perception and relevance of dreams in Gestalt therapy}

Dreams are rarely discussed theoretically in Gestalt therapy theory and in Gestalt theory, although dream work occupies a large and, above all, very valuable place in the practice of Gestalt therapy (Alban \& Groman, 1975; Holzinger, 2014a, p. 2, 2014b). In Gestalt therapy we assume that dreams hold existential messages for us that we should learn to understand (Feder, 1992). Dreams are fragmented the same way our personality is (Holzinger, 2013) and many parts of our personality are neither interconnected nor do they work together. They are there but still need to come together to become functional wholes, to become a complete Gestalt in order for an individual to work effectively. When working with dreams, the therapist is tempted to try to interpret, but Gestalt therapy is not an analytical but an integrative method (Gegenfurtner, 2005). Every interpretation by the therapist remains nothing more than a cognitive-intellectual game if the dreamer does not play an active role. A good example of how interpretation by the therapist can disrupt the free reflection on a dream by the dreamer are Freud's case study of Dora's dreams (Freud, 1905). It seems that Freud's interpretations often reflect his own associations and that another problem of these case reports are lack emotional content (Nobus et al., 2021). The dreamer, as mentioned before, knows a lot more about himself than the therapist and must be actively involved in the personal process of finding meaning. It is a question of learning, a question of revealing oneself (Holzinger, 2013). The Gestalt therapy supports the re-enactment and re-experiencing of the dream so that the dream can be grasped in its essence.

This is how Nicholas Pesant and Antonio Zadra summed it up (Pesant \& Zadra, 2004):

In the Gestalt approach of Perls (1992), all dream el- ements are understood as projections of the accepted or unwanted aspects of the dreamer's personality. [...] Gestalt dream work is sometimes viewed as a somatic approach, in that dreams are explored through the dreamer's bodily sensations during a session (p. 493f).

In Gestalt therapy, the dream is understood as a kind of 'development support': something existentially important takes place in it. Perceptions, sensations, feelings and experiences from the previous day are integrated into the already existing elements of the Gestalt of experience. According to this, the dream offers an opportunity to bring to light elements which are not yet integrated and thus opens up the potential to integrate them into the personality. Freud once called the dream the Via Regia, the royal path to the unconscious - and I believe that in reality it is the royal path to integration. I never know what the unconscious is, but we know that the dream is definitely the most immediate production there is for us. There is no expression more spontaneous than the dream (Perls, 1969). Gestalt theory and Gestalt therapy can, by their integrative concept, allow the thought that the unconscious per se (in a dream) can occur simultaneously with the superconscious or the ego instances: integration can occur.

In this vein Gestalt therapy dream work also assumes that everything that occurs in the dream is an aspect of the dreamer. This means that dreams can have several meanings and ultimately only the dreamer can understand the dream and know what the dream is about (Feder, 1992). I like to claim - as a rather rough definition - that dreams are feelings (and thoughts) in moving pictures.

In line with 'modern' dream researchers such as, Ernest Hartmann, who as a psychoanalyst has contributed to many studies to illuminate the dream (Walker, 2018), or the brain researcher Matthew Walker, who at the University of Berkeley studies brain structures that are active while dreams occur and also myself, we all adhere to the same thesis, although each of us use different words to describe it: The dream is a 'little psychotherapy' that we undertake every night to integrate new experiences into the background of the Gestalt of experience and of our individual perception of the world. The essential goal of Gestalt therapy is that we find our way back to our own strength by accepting split-off aspects of our personality (Feder, 1992; Hartmann-Kottek, 2000).

\section{Dream work in Gestalt therapy}

Of course, Gestalt therapy is only one of the different approaches for dream work, but it is the method that can be used in all kinds of dream experiences, not only in specific cases. It often happens, that excursions to other methods ultimately lead to the therapist falling back on Gestalt. The authors Gregory Scott Sparrow and Mark Thurston (Sparrow \& Thurston, 2010) openly admit that 'The Five Star Method' cannot be easily adapted to every dream and every therapeutic context. For instance, dreams that con- 
sist of single, static images - or for that matter, dreams in which the dreamer only observes the dream content, however active the other characters might be - do not avail themselves to this form of analysis. Except, that feelings and thoughts that arise in the course of such dreams can illuminate aspects of the dreamer's idiosyncratic response set. In such cases, the therapist can use Gestalt dialoguing or Jungian amplification, while reserving this intervention for those dreams that involve some interplay between the dreamer and the imagery. Even though Jung's analytical psychodrama (Beach, 2013) is an approach considered belonging to the schools of depth psychology it shows great congruence to the methods found in Gestalt Therapy. I therefore prefer to stick with the Gestalt from the start and fully use its potential.

Another way to see certain dreams is Kohut's perspective on self-state dreams (Kohut, 1977). These kinds of dreams, in his opinion, do not cover unconscious elements of the self but rather tensions that come from traumatic events which were threatening to one's self concept. Those dreams serve the function of protecting the self against those experiences.

Gestalt therapy is considered to be one of the most confrontational therapeutic methods. In Gestalt therapy, the dream is relived in the therapy session through identification, perception and confrontation (Gegenfurther, 2005). Therefore, it loses its terrifying content. Recently, Gestalt therapy has emerged as one of the most effective methods of treating diagnosed disorders that have nightmares as one of the symptoms, such as PTSD (Holzinger, 2018; Maercker, Rosner, \& Baumann, 2006).

The best known and probably most efficient 'tool' in Gestalt therapy is the role play 'the two chair method' (or 'empty chair and hot chair'). Typically, it takes place in a group setting. The client who wants to 'work' takes the 'hot seat' and, under the supervision of the therapist, projects whatever it is that needs to be integrated onto the empty chair for a dialogue and to achieve integration through this (Greenberg \& Dompierre, 1981).

As a Gestalt therapist I now also understand, that the Field (Lewin, 1963), in which the dreamer moves, helps shape the dream. In this sense, it does really matter who you tell a dream to. We only remember some dreams in the present or in conversation with a certain person. Many dreams simply cannot be remembered in certain contexts, sometimes because they are repressed, sometimes because they do not fit into the field. In this respect, the dream for me today is primarily an ideal mean of communication between the dreamer and the person to whom the dream is being told. A wonderful way to communicate and to share experiences on a poetic level, almost entirely free of restraints and control.

Specifically, in dream work we proceed as follows:

i) We ask the patient to tell the dream in the first person, in the present, as if the dream is happening right now.

ii) As a second step, we turn the patient into a stage di- rector: 'Please prepare a stage for your dream. Please speak as the dream character in the present tense, as if the dream is happening here and now. Take in turn all the roles of the people and objects that appear in your dream. Tell me what you experience and what you feel like in these roles.'

iii) As a third step, we focus on two dream characters who embody the main conflict.

iv) The dreamer expresses in the present what his counterpart said to him beforehand in a role play, in a manner appropriate for his age, in the language that fits to him. He speaks in the first-person: I... The role-playings are continued until the dream teller becomes aware that the representation coincides with the perceived feelings.

v) The main feeling that has emerged is expressed appropriately for the situation and then discussed with the therapist. The dream teller's next impulses are being asked: 'What do you want to do next? How to continue?'

These steps aim to ensure that the dreamer falls back into his or her sensory state of the dream as much as possible and that the right 'field' for recalling the dream is created.

\section{Development of the DreamSenseMemory}

'Getting involved' is the key word that led me to develop a new technique for dream work. Visual memories are the ones we humans mostly rely on, but often, when trying to picture in front of the inner eye, what the dreamer saw in the dream in order to tell it or to write it down, the dreamer takes an emotional distance in order to concentrate: by this a dream often gets deprived of its essence. Using all senses while telling a dream means getting fully involved, addressing each of the emotions and feelings triggered by what was seen, tasted, heard, smelled or felt: the whole self is at alert and the Gestalt can be completed. This technique is called DreamSenseMemory - a technique that Brigitte Holzinger developed from Gestalt therapy (as described above) and 'sense memory'.

Sense memory is one element of a technique by Lee Strasberg (Strasberg \& Morphos, 1988) known as method acting, which actors use to learn their subject. The aim is to 'commit' to the roles or scenes as intensively as possible using sensual memories and bring to light what works towards a certain role. The actors use their own experiences, their inner selves and feelings to bring the character they play to life, attaching them to the fictional character. The role is not only played anymore, it is felt and experienced, in order for that character to come to life. Method acting implies to first understand who the fictional character is, where does it stand in life, what is its goal and what just happened in its life. To achieve this the actor relies on: i) Affective memory, in which the actors were to remember their own experiences and transfer those to the 
fictional character; ii) Sense memory, where actors would rely on the memory of senses to recall sensory experiences similar to those the fictional character goes through; iii) Emotional memory, in which actors rely on their own emotional complexity to give life to their characters.

\section{Applying DreamSenseMemory}

The dream is the language of the psyche, a language of deep structures that tries to convey a message. The art of the therapist or of the dream worker consists in getting this message out as faithfully as possible. The psyche chooses all possible ways to bring this message to us. If someone tells a dream, the dreamer usually tries describing the scenes and sticks to the visual aspect. The first barrier to the hidden message of the dream is the spoken language: the word. The more precisely we try to formulate our thoughts, the more we withdraw from our feelings and emotions, which may have to do with the need to think logically in order to implement basic knowledge of grammar and syntax. Thus, the word can actually help lowering emotional distress, which implies lowering the intensity of emotions even if those do not lead to distress (Lieberman et al., 2007). The first task of dream work is opposite to it: not only figures and objects, but also emotions need to be uncovered first, in order for them to be understood and integrated. Subsequently, the soothing effect of putting the dream into words will contribute to the very effectiveness of the dream work session. Our way of communicating is through words, we have no other means for clear communication. Including more sense memory elements and their intensity, seems at this point to be the most effective way for countering the dampening effect of the word.

Therefore, during the whole dream work process, it is crucial for the therapist to pay attention to those non-verbal elements of communication like movements, facial expressions, diction, voice and intonation of the dreamer when telling the dream. The dreamer can be invited to move freely, to gesticulate if he feels like it, to walk around and possibly to physically re-enact the dream more vividly. Telling the dream in the present, in the first tense, while letting his body join the tale, will not only help him to bring back the dream to life, but it will also begin to address some of the senses, like a physical sensation of walking, touching objects or hearing the steps, remembering how loud he was screaming or laughing in his dream. Through questions related to senses, the memory of additional senses can be triggered. 'How cold was it?' 'What did the rose smell like?' 'Close your eyes, remember the scent of it!' 'Have you smelled this before in your waking life? When was that?'. Bringing the dreamer in the most similar state as during the dream seems advantageous having the encoding-specificity in mind. Additionally, studies implicate, that visualizations during dreams show very similar brain patterns as perception via the visual cortex during waking states (Horikawa, Tamaki, Miyawaki, \& Kamitani, 2013). Behavioural studies have demonstrated that smells trigger more vivid emotional memories than images (Herz, Eliassen, Beland, \& Souza, 2004), this was also found true for autobiographical memory (de Bruijn \& Bender, 2018). Thus, also in the frame of dream work, those senses can unlock what visual memories fail to address. The brain activity of the limbic system translates the memory of the odours into images and when memories are triggered by odours, there is more brain activity in areas associated with visual vividness (Arshamian et al., 2013). Bowen, Kark, and Kensinger (2018) proposed the NEVER (Negative Emotional Valence Enhances Recapitulation) model, its base are findings, that retrieval of memory is more successful when the encoding brain state can be reactivated and that emotions play a big role in those processes. It proposes that, compared to positive events, especially negative events are encoded based on detailed sensory input and that they produce greater similarity of sensory encoding and retrieval patterns. This is particularly relevant as the unconscious, suppressed parts of the whole self, that are studied via dreams, often stem from negative emotional events, and it also underpins the importance of reactivating the states that the sensory input initially produced.

In order to work with a dream, this dream needs to be remembered as intensively as possible: with the DSM method one manages to come as close to it as possible.

On a regular basis, I organize dream groups that meet once a week. We apply dream work according to Ullman's dream appreciation technique (Ullman, 1984) described in detail in a recent publication following an Event to honour the $120^{\text {th }}$ anniversary for Dora telling her dream to Freud (Nobus et al., 2021). This is a brief description of how we proceed with the Ullman's dream appreciation technique in our group: first, one person of the group tells or reads his/her dream, while the other members of the group take notes about what they hear. Then they can question the dreamer. At this stage, we already include many questions concerning more precise descriptions of what was perceived through the senses, of which feelings and emotions arose through it. The goal is to grasp as many details as possible and to uncover what is emotionally attached to those elements.

In the next stage, the dreamer listens to the members of the group, who tell the dream as if it was their own, imagining how they would feel in the dreamt situation, what this could mean to them.

The dreamer can now take back the dream and with the newly gained insights provided by the other group members, and shares, if willing to do so, his view, emotions and interpretation of it. At this point also the reallife background to the dream can become a topic, after which the members of the group might tell their interpretation of the dream. According to Ullman, if a group meets on a regular base, on the beginning of the next session, 
the dreamer can share the additional insights he gained after the first session (Ullman, 1984).

DSM is included in this process based on Ullman's method, in order to bring more elements of the dream to light.

During the process, the therapist's aim is to represent the concealed voices as truthfully as possible and to show how sensitive experiences at this depth can be and how we can bring them into life in a valuable way. Even in this group setting, his or her questions should therefore never influence the answer, but instead push the dreamer deeper into his memory world, allowing all the emerging emotions. The goal is to bring to light not only images, but the many intense emotions that possibly triggered those images or are triggered by them.

To prepare clients for our dream work session, I now use a dream diary in which the dream not only can be written down, but additional questions related to the senses can be easily filled out. I use two different models, one being electronical (an app) and the other is a book, in which small icons represent the senses involved. When taking notes, the dreamer does not need to use a lot of words and syntax while filling out the questionnaire, thus the perceived elements are not yet much dampened by the words in use. The questionnaire does help to uncover aspects of the dream connected to the senses, while also teaching the dreamers to pay more attention to the senses, thus creating additional awareness for the whole and all involved senses. On a long term, this leads not only to have more dream elements being recalled, thus supporting dream work, it also opens the path to mindfulness.

Clients using those tools as an introduction to DSM, are already more aware of the senses when telling their dreams in the therapy session. I usually start by asking them to choose a dream, preferable a recent dream, and tell it in present tense in as much detail as possible. I want the dreamer to re-enter and reexperience the dream as much as possible, as if it was happening now. This technique is inspired by Montague Ullman's dreamwork approach (Ullman, 1984) and the Gestalt approach of dream work (Holzinger, 2018).

After having been introduced to the DSM Method, Mr. M described his dream, as follows: At around 4 am I must have fallen asleep again. I dreamt: 'I am driving down the cemetery alley. This is the alley where our garden used to be. As I am driving down, a neighbour is waving at me: Look who's here! I am on my electric scooter driving down that narrow alley and look back to the right, and I see my late father-in-law. I am still driving, but then step on the emergency breaks, and turn back to my father-inlaw. He is on his knees gardening as always and says to me, if I remember correctly, he says: 'Actually it is better now, before it was not as good. Now it is better.'I am contemplating his words and my feeling is, that he wants to tell me, that that the way he does it, it is better, than my way. This was always his garden, his work that he did, my work always was inferior and I have the feeling at that moment, that I have not worked good enough. That really bothered me, but I got back on my scooter without any emotions and drove a few meters, but am then looking for my car. Where is my car? I don't find my car. The car is gone. I take my telephone and make a phone call. I hear a voice very similar to my wives, but belonging to an entirely different person. I continue my driving, somehow I got my car back. The car is back again. I drive outside and then I have, I have, ... The day before, I was working in my garden, the tomato plants were black on the edges because of a fungus. It is about that garden. When one dreams, the nose is in it. I often dream with my nose, I hear very well in my dreams as well. In the dream on the edges of the tomato plants was feces. Strange. And then I took the tomato plants and put them in the toilet and flushed them down. This was the end of the dream.'

I asked the dreamer to enter the dream again by focusing on sensual impressions of elements like the road or the tomatoes, mentioning potential memories that come to mind while doing so until I am under the impression, that I have been able to grasp the moving pictures of the dream myself.

To be noted, at the end of the dream it wasn't quite clear what belonged to the dream, what is explanation or association. Also, the dreamer often fell into past tense as if it was difficult to stay in the present tense of the dream plot. Of course, a dream story contains many aspects. I will only pick a few that seem relevant to demonstrate the DSM approach in more detail.

While talking about the road and detailed aspects of it, I ask the dreamer, how it felt to move along the road, searching for bodily sensations according to DSM. He described the alley with an air of emptiness, not looking left or right. He told me he often flies in his dream, as being on the run. This time, the sensational quality was similar, and sensually reminded him of being on the run. But this time he stops, uses emergency breaks and faces the fatherin-law, whom he almost had missed.

Dreams are mostly images from life, that we have experienced, often in an order that seems inexplicable at first. The 'cuts' of the dreams are also interesting, why a dream breaks off at a certain point, why the picture ends and something new is in the room. In the case of Mr. M., the cut is in the moment when he e.g. uses the emergency breaks, he finds his father-in-law speaking and saying something else than expected.

The dreamer further mentions, that his garden is now near the father-in-law's garden, but described it more than twice as big. He also mentioned, that the tomato plants were his father-in-law's favourite plants and are also his favourite plants.

He remembers, in the dream, he was working with his tomato plants finding them with fungus/feces like blackness on the edges. He reported they were spreading a revolting odour, which the dreamer experienced vividly. He 
found that strange, he said, but then threw the plants into the toilet and flushed them down because of the revolting odour and the sentence spoken by the father-in-law. Now that he worked with his dream according to DSM, he started feeling as he always felt: Put down and humiliated by his father-in-law. He reexperiences that he made him feel like he did nothing right, literally worth feces to be thrown into the toilet, making this long overdue rottenness disappear.

He then remembered, that his father-in-law also said 'it is better now'. After telling the dream several times and working with it by the ways of DSM, he slowly realized, that in real life he now has a way nicer and bigger garden than his father-in-law ever had. He comes up with the notion, that actually the father-in-law of the dream world might have changed and tried to make him understand that his garden now is in better shape, acknowledging his skills like he never has in real life.

It was the sensual memory of the odour and hearing the sentence the father-in-law spoke and 'feeling' those elements, that might have led the dreamer to noticing another 'strange' behaviour, namely throwing the plants into the toilet and flushing them down. This may not be the best solution to cope with revolting sensations, like being humiliated or not accepted by the father-in-law, but it is a way to simply bearing it. As a side remark, he is moving down the cemetery road and the father-in-law has in waking life passed a long time ago, which may play a role in the evolvement of the dream as well, of course.

In the course of the DSM session entering the sensual world of the dreamer, it also came up, that the dreamer's vision in waking life is quite impaired. Therefore, he used his other senses, such as hearing, smelling and kinaesthetic movement more intensely. This is a nice observation for our notion, that dreams might help us process our sensations of the daily life.

The sensual memory of flying, hearing and smelling triggered the reexperiencing of a problematic relationship in the dream and already started to change its unpleasantness for the dreamer. Additionally, by making it accessible through the memory of the senses, focusing on it consciously and putting it in words, DSM transferred the change that had started in the dream to waking life until the business is finished.

\section{Conclusions}

To summarize, DSM is a way of dream work that is easy to access and learn. It allows to explore the effect dreams have into the waking state by recalling them in as much detail and as sensually as possible, just like an actor/actress does when entering a new role. This is important as we assume, that dreams particularly help processing sensual experiences made during the day. This forms the biggest difference to other 'dreamwork techniques': DSM does not emphasize on interpreting or analysing the dream cognitively, but on sensually 'feeling' the dream. The access to the dream and the memory of the dream takes place through the memory of perception and sensation, hence the name DreamSenseMemory. By approaching the dream memory through sensual awareness, it is easier for the dreamer to intuitively 'grasp' what the dream was moved by, psychodynamically. By reexperiencing the dream with all senses it allows for an emerging understanding of the dream and of what it may try to integrate, serving inner growth and adaptation. Hence DSM can be applied in the process of psychotherapy, but can also be integrated into everyday life. For this reason our App called DreamSenseMemory was developed, that can be used to deal with dreams in a productive, inspiring way and help satisfy the desire for dream interpretation. Even though we think DSM is more effective if it was introduced in a therapeutic setting, the app helps amplify the ability of dreams to process sensual perceptions of the day. Benefits are not only the development of a more and more intuitive understanding of the dream, but also an easier access to the dreamers perception, sensual awareness, emotions, feelings and experiences.

\section{References}

Abrahan, V. D., Shifres, F., \& Justel, N. (2021). Music improvisation enhances neutral verbal and visual memory in musicians and non-musicians alike. The Arts in Psychotherapy, 75, 101807. doi: 10.1016/j.aip.2021.101807.

Alban, L. S., \& Groman, W. D. (1975). Dreamwork in a Gestalt therapy context. The American Journal of Psychoanalysis, 35(2), 147-156. doi: 10.1007/BF01358186.

Arshamian, A., Iannilli, E., Gerber, J. C., Willander, J., Persson, J., Seo, H.-S., Hummel, T., \& Larsson, M. (2013). The functional neuroanatomy of odour evoked autobiographical memories cued by odours and words. Neuropsychologia, 51(1), 123-131. doi: 10.1016/j.neuropsychologia.2012.10.023.

Beach, C. (2013). Using psychodrama in analysis. In Jung and Moreno (pp. 129-147). London: Routledge.

Bowen, H. J., Kark, S. M., \& Kensinger, E. A. (2018). NEVER forget: Negative emotional valence enhances recapitulation. Psychonomic Bulletin \& Review, 25(3), 870-891. doi: 10.3758/s13423-017-1313-9.

Bowman, C. E., \& Nevis, E. C. (2005). The History and Development of Gestalt Therapy. In A. Woldt \& S. Toman, Gestalt Therapy: History, Theory, and Practice (pp. 3-20). Newcastle upon Tyne: SAGE Publications, Inc. doi: 10.4135/ 9781452225661.n1.

Busch, H.-J., Leuzinger-Bohleber, M., \& Prokop, U. (2003). Sprache, Sinn und Unbewusstes: Zum 80. Geburtstag von Alfred Lorenzer. Tübingen: Edition Diskord.

de Bruijn, M. J., \& Bender, M. (2018). Olfactory cues are more effective than visual cues in experimentally triggering autobiographical memories. Memory, 26(4), 547-558. doi: 10.1080/09658211.2017.1381744.

Edwards, D. J. (1989). Cognitive restructuring through guided imagery. In Comprehensive handbook of cognitive therapy (pp. 283-297). Berlin: Springer.

Ehrenfels, C. von. (1890). Über Gestaltqualitäten. Vierteljahrss- 
chrift Für Wissenschaftliche Philosophie, 14(3), 249-292.

Feder, B. (1992). Peeling the onion: A Gestalt therapy manual for clients (R. Ronall \& B. Feder, Eds.). Bud Feder.

Flexser, A. J., \& Tulving, E. (1978). Retrieval independence in recognition and recall. Psychological Review, 85(3), 153-171. doi: 10.1037/0033-295X.85.3.153.

Freud, S. (1900) Die Traumdeutung. Wien: Deuticke. (transl.: Freud, S., \& Crick, J. (1999). Sigmund Freud the interpretation of dreams. Trans. Joyce Crick. Oxford: Oxford University Press).

Freud, S. (1905). Fragment of an analysis of a case of hysteria. In The standard edition of the complete psychological works of Sigmund Freud, Volume vii (1901-1905): A case of hysteria, three essays on sexuality and other works (pp. 1-122). Trans. James Strachey, Anna Freud, Alix Strachey and Alan Tyson. London: Vintage.

Gegenfurtner, N. (2005). Eine empirische Studie über die gestalttherapeutische Arbeit mit Träumen - Prozessanalysen von Klienten- und Therapeutenverhalten im Rahmen von 30 Therapiestunden. Monaco: Ludwig-Maximilians-Universität.

Greenberg, L. S., \& Dompierre, L. M. (1981). Specific effects of Gestalt two-chair dialogue on intrapsychic conflict in counseling. Journal of Counseling Psychology, 28(4), 288-294. doi: 10.1037/0022-0167.28.4.288.

Hartmann-Kottek, L. (2000). Gestalttherapie. In C. Reimer \& U. Rüger (Eds.), Psychodynamische Psychotherapien: Lehrbuch der tiefenpsychologisch orientierten Psychotherapien (pp. 177-233). Berlin-Heidelberg: Springer. doi: 10.1007/978-3662-12851-0_11.

Herz, R. S., Eliassen, J., Beland, S., \& Souza, T. (2004). Neuroimaging evidence for the emotional potency of odourevoked memory. Neuropsychologia, 42(3), 371-378. doi: 10.1016/j.neuropsychologia.2003.08.009.

Holzinger, B. (2013). Albträume - was sie uns sagen und wie wir sie verändern können. Monaco: Nymphenburger Verlag.

Holzinger, B. (2014a). Lucid dreaming in psychotherapy. In Lucid dreaming: New perspectives on consciousness in sleep: Science, psychology, and education; Religion, creativity, and culture, Vols. 1-2 (pp. 37-61). Santa Barbara, CA: Praeger/ ABC-CLIO.

Holzinger, B. (2014b). 'Dream Sense Memory' Traumarbeit in der Gestalttherapie und die psychotherapeutische Technik des luziden Träumens. Psychotherapie Forum, 19(3), 111-120. doi: 10.1007/s00729-014-0024-1.

Holzinger, B. (2018). To Dream - Perchance to Sleep (B. Feder, Ed.; L. Cosentino, Trans.; 2nd ed.). Stuttgart: Klett-Cotta Verlag.

Holzinger, B., \& Klösch, G. (2013). Schlafchoaching: Wer wach sein will, muss schlafen [Sleep coaching: Who wants to be awake needs to sleep, in German]. Berlin: Goldegg Verlag $\mathrm{GmbH}$.

Horikawa, T., Tamaki, M., Miyawaki, Y., \& Kamitani, Y. (2013). Neural decoding of visual imagery during sleep. Science, 340(6132), 639-642. doi: 10.1126/science.1234330.

Koffka, K. (1935). Principles of Gestalt psychology. London: Kegan Paul.
Kohut, H. (1977). The Restoration of the Self. New York, NY: International Universities Press.

Lewin, K. (1963). Feldtheorie in den Sozialwissenschaften. Göttingen: Verlag Hans Huber.

Lieberman, M. D., Eisenberger, N. I., Crockett, M. J., Tom, S. M., Pfeifer, J. H., \& Way, B. M. (2007). Putting Feelings Into Words. Psychological Science, 18(5), 421-428. doi: 10.1111/j.1467-9280.2007.01916.x.

Maercker, A., Rosner, R., \& Baumann, K. (Eds.). (2006). Psychotherapie der posttraumatischen Belastungsstörungen: Krankheitsmodelle und Therapiepraxis - störungsspezifisch und schulenübergreifend; 11 Tabellen (1. Aufl). New York, NY: Thieme.

Majid, A., \& Levinson, S. C. (2011). The Senses in language and culture. The Senses and Society, 6(1), 5-18. doi: 10.2752/174589311X12893982233551.

Metzger, W. (1936). Gesetze des Sehens (4th ed.). Klotz.

Nobus, D., Lockheart, J., Holzinger, B., Adler, K., Barrett, D., Wessely, Z., \& Blagrove, M. (2021). 120th Anniversary Event for Dora Telling Her Burning House Dream to Freud. International Journal of Dream Research, 14(2), 1-16.

Perls, F. S. (1969). Gestalt-Therapie in Aktion. Stuttgart: Ernst Klett.

Perls, F. S. (1972). In and out the garbage pail. New York, NY: Bantam Books.

Perls, F. S., Hefferline, R. F., Goodman, P., \& Perls, F. S. (1995). Gestaltherapie: Grundlagen (3. Aufl). Monaco: Dt. Taschenbuchverl.

Perls, L. (1992). Concepts and misconceptions of Gestalt therapy. Journal of Humanistic Psychology, 32(3), 50-56. doi: 10.1177/0022167892323004.

Pesant, N., \& Zadra, A. (2004). Working with dreams in therapy: What do we know and what should we do? Clinical Psychology Review, 24(5), 489-512. doi: 10.1016/j.cpr.2004.05.002.

Plümacher, M., \& Holz, P. (Eds.). (2007). Speaking of colors and odours. Amsterdam: John Benjamins Pub.

Sparrow, G. S., \& Thurston, M. (2010). The five star method: a relational dream work methodology. Journal of Creativity in Mental Health, 5(2), 204-215. doi: 10.1080/15401383. 2010.485113.

Strasberg, L., \& Morphos, E. (1988). A dream of passion: The development of the method. New York, NY: New American Library.

Tulving, E., \& Thomson, D. M. (1973). Encoding specificity and retrieval processes in episodic memory. Psychological Review, 80(5), 352-373. doi: 10.1037/h0020071.

Ullman, M. (1984). Group dream work and healing. Contemporary Psychoanalysis, 20(1), 120-130. doi: 10.1080/00107530. 1984.10745718.

Wagemans, J. (2015). Historical and conceptual background: Gestalt theory. In Oxford Handbook of Perceptual Organization (p. 22). Oxford: Oxford University Press.

Walker, M. (2018). Why we sleep: The new science of sleep and dreams. London: Penguin Books.

Yontef, G. M. (1993). Awareness dialogue \& process: Essays on gestalt therapy. Santa Barbara, CA: Gestalt Journal Press. 